\title{
Neural Mechanisms Underlying Probabilistic Category Learning in Normal Aging
}

\author{
Francesco Fera, ${ }^{1,2 *}$ Thomas W. Weickert, ${ }^{1 \star}$ Terry E. Goldberg, ${ }^{1}$ Alessandro Tessitore, ${ }^{1,3}$ Ahmad Hariri, ${ }^{1,4}$ Sumitra Das, ${ }^{1}$ \\ Sam Lee, ${ }^{1}$ Brad Zoltick, ${ }^{1}$ Martijn Meeter, ${ }^{5}$ Catherine E. Myers, ${ }^{6}$ Mark A. Gluck, ${ }^{7}$ Daniel R. Weinberger, ${ }^{1}$ and \\ Venkata S. Mattay ${ }^{1}$ \\ ${ }^{1}$ Clinical Brain Disorders Branch, National Institute of Mental Health, National Institutes of Health, Department of Health and Human Services, Bethesda, \\ Maryland 20892, ${ }^{2}$ Neuroimaging Laboratory, Neurological Sciences Institute, National Research Council, 87050 Cosenza, Italy, ${ }^{3}$ Second Division of \\ Neurology, Department of Neuroscience, Second University of Naples, 80131 Naples, Italy, ${ }^{4}$ Department of Psychiatry, University of Pittsburgh School of \\ Medicine, Pittsburgh, Pennsylvania 15213, ${ }^{5}$ Department of Cognitive Psychology, Vrije Universiteit Amsterdam, NL 1081 BT Amsterdam, The Netherlands, \\ and ${ }^{6}$ Department of Psychology and ${ }^{7}$ Center for Molecular and Behavioral Neuroscience, Rutgers University, Newark, New Jersey 07102
}

Probabilistic category learning engages neural circuitry that includes the prefrontal cortex and caudate nucleus, two regions that show prominent changes with normal aging. However, the specific contributions of these brain regions are uncertain, and the effects of normal aging have not been examined previously in probabilistic category learning. In the present study, using a blood oxygenation leveldependent functional magnetic resonance imaging block design, 18 healthy young adults (mean age, $25.5 \pm 2.6$ years) and 15 older adults (mean age, $67.1 \pm 5.3$ years) were assessed on the probabilistic category learning "weather prediction" test. Whole-brain functional images acquired using a 1.5T scanner (General Electric, Milwaukee, WI) with gradient echo, echo planar imaging (3/1 mm; repetition time, $3000 \mathrm{~ms}$; echo time, $50 \mathrm{~ms}$ ) were analyzed using second-level random-effects procedures [SPM99 (Statistical Parametric Mapping)]. Young and older adults displayed equivalent probabilistic category learning curves, used similar strategies, and activated analogous neural networks, including the prefrontal and parietal cortices and the caudate nucleus. However, the extent of caudate and prefrontal activation was less and parietal activation was greater in older participants. The percentage correct and reaction time were mainly positively correlated with caudate and prefrontal activation in young individuals but positively correlated with prefrontal and parietal cortices in older individuals. Differential activation within a circumscribed neural network in the context of equivalent learning suggests that some brain regions, such as the parietal cortices, may provide a compensatory mechanism for healthy older adults in the context of deficient prefrontal cortex and caudate nuclei responses.

Key words: prefrontal cortex; parietal cortex; caudate nucleus; aging; category learning; compensation

\section{Introduction}

Normal aging is associated with neural and metabolic inefficiency that may account for age-related decline in the cognitive declarative mnemonic processes of working memory (Grady et al., 1998; McIntosh et al., 1999), episodic memory (Schacter et al., 1996; Cabeza et al., 1997; Anderson et al., 2000), and semantic memory (Madden et al., 1996; Cabeza et al., 1997; Anderson et al., 2000). Healthy older adults show prefrontal cortex volumetric reductions (Raz et al., 1997) and impaired declarative memory characterized by prefrontal cortex dysfunction (Rosen et al., 2002). Other studies report age-associated declines in caudate nucleus volume (Jernigan et al., 1991, 2001a,b; Raz et al., 2003)

\footnotetext{
Received July 1, 2005; revised 0ct. 20, 2005; accepted 0ct. 23, 2005.

This work was supported by the Intramural Research Program of the National Institute of Mental HealthNational Institutes of Health.

*F.F. and T.W.W. contributed equally to this work.

Correspondence should be addressed to Dr. Venkata S. Mattay, Clinical Brain Disorders Branch, National Institute of Mental Health, National Institutes of Health, Building 10, Room 3C108, Bethesda, MD 20892. E-mail: vsm@mail.nih.gov.

DOI:10.1523/JNEUROSCI.2736-05.2005

Copyright $\odot 2005$ Society for Neuroscience $\quad$ 0270-6474/05/2511340-09\$15.00/0
}

and function (Volkow et al., 1998; Rypma et al., 2001; van Dyck et al., 2002).

Studies of normal aging typically show a relative preservation of nondeclarative learning (Howard and Howard, 1992, 1997; La Voie and Light, 1994; Light et al., 1995; Maki et al., 1999). Functional neuroimaging studies examining nondeclarative learning during normal aging report similar activation patterns in young and older adults performing word-stem completion (Backman et al., 1997), repetition priming (Lustig and Buckner, 2004), and serial reaction time tasks (Daselaar et al., 2003). Because there are multiple forms of nondeclarative learning (Cohen and Squire, 1980; Squire, 1992a,b) relying on distinct neural substrates (Knowlton et al., 1996a,b; Reber et al., 1998a,b, 2002), it is not clear whether all nondeclarative processes will be spared by brain aging. Furthermore, findings of preserved nondeclarative learning during normal aging do not preclude the existence of functional reorganization of neural connectivity or cognitive processing with advancing age.

The neural circuitry associated with age-related, nondeclarative probabilistic category learning has not been reported. Probabilistic category learning involves gradual learning without 
conscious appreciation of successful rules or strategies. Previous studies of probabilistic category learning administering the "weather prediction" task to patients with striatal dysfunction suggest that this type of nondeclarative learning is related to striatum function (Knowlton et al., 1994, 1996a,b). Functional neuroimaging studies examing probabilistic category learning in healthy young adults has reliably demonstrated activation of a neural network that includes the caudate nucleus and the prefrontal and parietal cortices (Poldrack et al., 1999, 2001; Aron et al., 2004). However, the role of the prefrontal and parietal cortices in probabilistic category learning is not understood.

The present study investigated the effect of aging on the physiological mechanisms underlying probabilistic category learning using a version of the weather prediction task demonstrated previously to elicit dorsolateral prefrontal cortex and striatal activity in healthy young adults (Poldrack et al., 1999, 2001). Based on age-related volumetric and functional alterations of the prefrontal cortex and caudate nucleus, the hypothesis for the present study posits differential probabilistic category learning and activation patterns between healthy young and older adults. If normal dorsolateral prefrontal cortex and caudate nucleus function is relevant to probabilistic category learning, then age-related alterations of these brain regions should be displayed as decreased activation and learning in otherwise healthy older adults.

\section{Materials and Methods}

Participants

Thirty-three healthy participants, 18 young adults ( 9 males and 9 females; mean age, $25.5 \pm 2.6$ years) and 15 older adults ( 9 males and 6 females; mean age, $67.1 \pm 5.3$ years) recruited from the National Institutes of Health (NIH) and the surrounding community through the NIH Normal Volunteer Office participated in this study. The mean years of education were not significantly different between young (mean, 16.7; $\mathrm{SD}, 2.5)$ and older (mean, $16.8 ; \mathrm{SD}, 2.2)$ adults $\left(t_{(23)}=0.11 ; p=0.91\right)$. All participants were screened for past and present history of neurological, psychiatric, or medical problems, as well as current medication use (except birth control pills in young women and hormonal substitution therapy in postmenopausal women). Written, informed consent was obtained from each person who participated in the study, which was approved by the Intramural Review Board of the National Institute of Mental Health. In all participants who had visual refractive abnormalities, corrections were achieved with prescription contact lenses or magnetic resonance imaging (MRI)-compatible plastic lenses in a plastic frame.

\section{Probabilistic category learning test}

A version of the probabilistic category learning weather prediction task (Poldrack et al., 1999) allowed alternation of the experimental weather prediction task with a perceptual-motor control task. Before entering the scanner, all participants were given instructions for both tasks. For the weather prediction task, participants were told that they should make a decision to predict rain or shine on the basis of four distinct cue cards that would be presented either individually or in combinations of up to three cards. They were also told that they should guess at first but gradually they would improve at determining which cue card combinations predict rain or shine. In this probabilistic category learning task, participants learn the relationship between two equally occurring outcome variables (rain or shine) and combinations of four cue cards, each composed of simple geometric shapes (Fig. 1a), gradually and presumably without conscious awareness. The relationship between cue cards and outcome variables was predetermined on a probabilistic basis (see Table 1 for the cue-outcome probability schedule), and presentations were randomized with the constraint that identical cue combinations would not appear consecutively and each outcome (rain or shine) was limited to five consecutive occurrences. For the perceptual-motor control task, all participants were instructed to determine whether or not two of four identical cue cards were presented during each trial, with the cue cards being a.
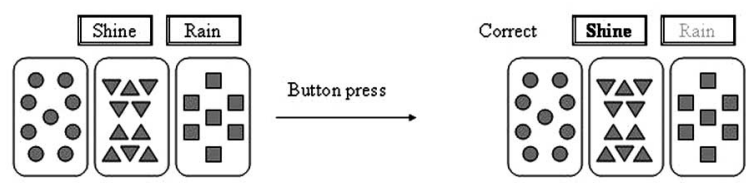

b.
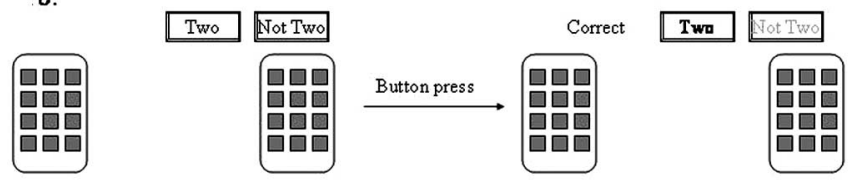

Figure 1. Sample probabilistic learning (weather prediction) ( $\boldsymbol{a}$ ) and perceptual-motor control task $(\boldsymbol{b})$ trials.

Table 1. Probability structure of the probabilistic learning (weather prediction) task

\begin{tabular}{lllllll}
\hline & \multicolumn{7}{l}{ Cue } & & & & \\
\cline { 2 - 5 } Cue pattern & 1 & 2 & 3 & 4 & $p$ (cue combination) & $p$ (outcome) \\
\hline 1 & 0 & 0 & 0 & 1 & 0.133 & 0.150 \\
2 & 0 & 0 & 1 & 0 & 0.087 & 0.385 \\
3 & 0 & 0 & 1 & 1 & 0.080 & 0.083 \\
4 & 0 & 1 & 0 & 0 & 0.087 & 0.615 \\
5 & 0 & 1 & 0 & 1 & 0.067 & 0.200 \\
6 & 0 & 1 & 1 & 0 & 0.040 & 0.500 \\
7 & 0 & 1 & 1 & 1 & 0.047 & 0.143 \\
8 & 1 & 0 & 0 & 0 & 0.133 & 0.850 \\
9 & 1 & 0 & 0 & 1 & 0.067 & 0.500 \\
10 & 1 & 0 & 1 & 0 & 0.067 & 0.800 \\
11 & 1 & 0 & 1 & 1 & 0.033 & 0.400 \\
12 & 1 & 1 & 0 & 0 & 0.080 & 0.917 \\
13 & 1 & 1 & 0 & 1 & 0.033 & 0.600 \\
14 & 1 & 1 & 1 & 0 & 0.047 & 0.857 \\
\hline
\end{tabular}

For any given trial, one of the 14 possible cue pattern combinations displayed above appeared on the computer screen with a probability indicated as $p$ (cue combination). As shown above, the probability of the cue combinations to predict "sunshine" (outcome 1) was set at $p$ (outcome). Conversely, the probability of the above cue combinations to predict "rain" (or outcome 2) was equal to $1-p$.

presented either individually or in combinations of up to three cards. See Figure $1 b$ for the perceptual-motor control task stimuli. Presentations of the perceptual-motor control stimuli were randomized with the constraint that identical spatial positions of the four cards did not appear consecutively and each outcome (two or not two) was limited to five consecutive occurrences. Stimuli for both tasks (weather prediction and control) were presented via a back-projection system, and behavioral responses, left (for "shine" or "two") or right (for "rain" or "not two") button presses with the right thumb, were recorded via a fiber optic response box (Current Designs, Philadelphia, PA). All stimuli were displayed on the screen for $4.5 \mathrm{~s}$ with an intertrial interval of $0.5 \mathrm{~s}$. After each response for both experimental and control tasks, the words "correct" or "incorrect" appeared as feedback to the participant, and missed trials were not included in the scoring.

\section{Scanning procedure}

Using a quadrature head coil transceiver, the functional MRI (fMRI) study was performed on a 1.5T MR system (General Electric, Milwaukee, WI) equipped with gradients capable of generating gradient fields of 40 $\mathrm{mT} / \mathrm{m}$ with a slew-rate of $180 \mathrm{~T} / \mathrm{m} / \mathrm{s}$. For the blood oxygenation leveldependent (BOLD) fMRI experiment, a gradient echo, echo planar imaging sequence was used that acquired single-shot images with a matrix size of $64 \times 64$ over a field of view of $200 \times 200 \mathrm{~mm}^{2}$, for a nominal in-plane resolution of $3.125 \times 3.125 \mathrm{~mm}^{2}$. Thirty axial slices $(3 \mathrm{~mm}$ thickness, $1 \mathrm{~mm}$ gap) were oriented inferior to superior to cover the entire brain. Repetition time, echo time, and flip angle were $3.0 \mathrm{~s}, 50 \mathrm{~ms}$, and $90^{\circ}$, respectively. The experimental paradigm consisted of a simple box-car design with eight cycles during which 30 s blocks of probabilistic category learning stimuli (six trials per block) alternated with $30 \mathrm{~s}$ blocks 
of perceptual-motor control task stimuli (six trials per block). Each participant received two runs, with each run consisting of 48 weather prediction and 48 perceptual-motor control trials. One hundred sixty scans were collected in a total scan time of 8 min per fMRI run, giving a total of 96 trials for each task. Task order (probabilistic category learning or perceptual-motor control) was counterbalanced across participants and gender.

\section{Data analysis}

Behavioral data. The percentage correct and reaction times were used as measures of learning the cue-outcome associations during probabilistic category learning. Transformed cumulative percentage correct scores and reaction times were analyzed using separate two-way, repeatedmeasures ANOVAs with young and older adults as the between-subjects variable. Additionally, a separate independent $t$ test was used to determine group differences with respect to trials on which no responses were made. An identical series of analyses were applied to the perceptualmotor control task data. Because reaction time differences were expected between young and older adults, reaction time data were adjusted to provide cognitive processing speed scores during probabilistic category learning for each group by computing the weather prediction minus control task reaction time difference score and dividing by the control task reaction time at each quartile. These adjusted scores were entered into a separate two-way, repeated-measures ANOVA to determine whether cognitive processing speed differed between groups.

Strategy analyses. Because recent work (Gluck et al., 2002) suggests that the strategy used to perform the weather prediction task may influence performance, data from the present study were also analyzed using an improved version of the strategy-clustering analysis originally developed by Gluck et al. (2002). This revised analysis assigns blocks of trials from individual participants to strategies on the basis of the response pattern (M. Meeter, C. E. Myers, D. Shohamy, R. M. Hopkins, and M. A. Gluck, unpublished observation). Assigned strategies were either complex (multi-cue strategy), in which participants base their response on the entire configuration of cards, simple (singleton strategy), in which participants respond consistently only to one-card patterns, or intermediate (single-cue strategy) based on the presence/absence of one card in a twoto three-card combination. Details of the strategy classifications are explained in the study by Gluck et al. (2002). A revised version of the algorithm of Gluck et al. (2002) was used to determine which strategy best fit the performance data of each participant. If the response pattern of a participant did not conform to any of the strategies described above, the performance was categorized as "no detectable strategy." However, classification as such does not necessarily imply that a participant did not use a strategy or strategies; instead they may have used idiosyncratic or probabilistic strategies that were not identified, or they may have switched too rapidly between strategies so that no consistent pattern emerged. The frequency of each strategy used in both the young and older groups was compared using a $\chi^{2}$ analysis to establish whether the two groups used qualitatively different strategies to solve the probabilistic category learning task.

Imaging data. These data were processed off-line on a Linux workstation, using the general linear model of SPM99 (Statistical Parametric Mapping). Images for each participant were realigned to the eighth volume in the time series to correct for head motion, spatially normalized into a standard stereotactic space (Montreal Neurological Institute template) using a 12-parameter affine model, and smoothed to minimize noise and residual differences in gyral anatomy with a Gaussian filter set at $6 \mathrm{~mm}$ full-width at half-maximum. Voxel-wise signal intensities were ratio normalized to the whole-brain global mean. Data sets were also screened for high quality (scan stability) as demonstrated by small motion correction $(<2 \mathrm{~mm})$. To better evaluate the temporal dynamics of learning-related BOLD changes, the time series data were divided into four quartiles of 80 scans each, with 24 weather prediction and 24 perceptual-motor control trials in each quartile.

As a first level of analysis, predetermined condition effects at each voxel were calculated using a $t$ statistic, producing a statistical image for the contrast of weather prediction versus perceptual-motor control tasks for each quartile and for each participant. These individual contrast im-
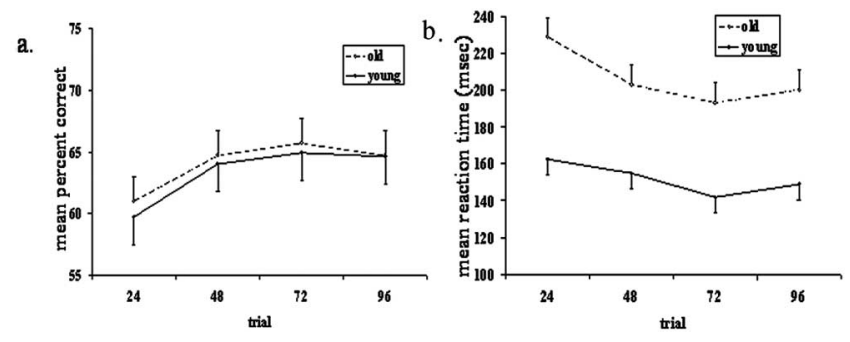

Figure 2. Cumulative percentage correct $(\boldsymbol{a})$ and reaction time $(\boldsymbol{b})$ for each trial block in young and older adults.

ages were then used in a conservative second-level random-effects model that accounts for both scan-to-scan and subject-to-subject variability using one-sample $t$ tests for main effects of condition within each quartile $(p<0.0025)$. Time-by-condition interactions across quartiles were also performed with a paired $t$ test $(p<0.05)$. The young and older adult samples were tested for a group-by-condition interaction using a oneway ANOVA with $p<0.05$. The relationship between probabilistic learning using percentage correct responses per quartile and activation was assessed using simple regression analyses with $p<0.05$.

An additional analysis was performed in the older adult group to explore whether group differences in activation patterns might be an artifact of spatial normalization arising from group differences in brain morphology (e.g., ventricular size), particularly near the caudate nuclei. In this analysis, the realigned images of the older adults were spatially normalized onto a specific older adult template (A. Janke; http://www.cmr. uq.edu.au/ rotor/models/) using a 12-parameter affine model and smoothed as outlined above to minimize noise and residual differences in gyral anatomy with a Gaussian filter set at $6 \mathrm{~mm}$ full-width at halfmaximum. Statistical images for the contrast of weather prediction versus perceptual-motor control tasks for each quartile and for each participant were again created as outlined above using a $t$ statistic. These individual contrast images were then used in a conservative second-level, random-effects model using one-sample $t$ tests for main effects of condition within each quartile $(p<0.0025)$.

\section{Results}

\section{Probabilistic category learning}

Both young and older adults displayed equivalent learning. Results of the two-way, repeated-measures ANOVA for percentage correct demonstrated no significant main effect of group $\left(F_{(1,31)}=0.07 ; p=0.80\right)$, a significant main effect of trial $\left(F_{(3,93)}=6.05 ; p<0.001\right)$, and no significant group-by-trial interaction $\left(F_{(3,93)}=0.07 ; p=0.97\right)$. Regarding reaction times, a separate two-way, repeated-measures ANOVA displayed a significant main effect of group $\left(F_{(1,31)}=22.31 ; p<0.001\right)$, a significant main effect of trial $\left(F_{(3,93)}=8.31 ; p<0.001\right)$, and no significant group-by-trial interaction $\left(F_{(3,93)}=0.96 ; p=\right.$ $0.41)$. A post hoc Fisher's LSD test of the significant main effect of group revealed that the older participants were significantly slower than the young $(p<0.001)$. See Figure $2, a$ and $b$, for the cumulative percentage correct and reaction time across trials in young and older adults. Results of a separate independent $t$ test for the number of trials on which no responses were made displayed a significant group difference between young (mean, 0.2; $\mathrm{SD}, 0.7)$ and older (mean, $2.1 ; \mathrm{SD}, 2.6)$ adults $\left(t_{(31)}=2.85 ; p=\right.$ $0.008)$. However, the total number of omissions in the older adults was $<2 \%$ of total trials.

ANOVA for percentage correct during the perceptual-motor control task displayed a nonsignificant trend for a main effect of group $\left(F_{(1,31)}=3.29 ; p=0.08\right)$, a significant main effect of trial $\left(F_{(3,93)}=9.73 ; p<0.001\right)$, and no significant group-by-trial interaction $\left(F_{(3,93)}=2.09 ; p=0.11\right)$. ANOVA examining the 
Table 2. Mean reaction time (in milliseconds) during the perceptual-motor control task and cognitive processing speed (in milliseconds) during the probabilistic category learning in healthy young and older adults

\begin{tabular}{lcccr}
\hline & Quartile 1 & \multicolumn{1}{c}{ Quartile 2 } & \multicolumn{1}{c}{ Quartile 3 } & \multicolumn{1}{c}{ Quartile 4 } \\
\hline $\begin{array}{l}\text { Perceptual-motor control } \\
\quad \text { Older adults }\end{array}$ & $1599.5(153.0)$ & $1481.0(165.8)$ & $1184.2(82.2)$ & $1150.0(84.4)$ \\
$\quad$ Young adults & $1094.6(139.6)$ & $1038.8(151.3)$ & $1003.3(75.0)$ & $987.0(77.1)$ \\
$\begin{array}{l}\text { Cognitive processing speed } \\
\quad \text { Older adults }\end{array}$ & $0.60(0.11)$ & $0.59(0.12)$ & $0.66(0.06)$ & $0.77(0.09)$ \\
$\quad$ Young adults & $0.54(0.11)$ & $0.56(0.10)$ & $0.49(0.09)$ & $0.58(0.09)$ \\
\hline
\end{tabular}

SE values are in parentheses. Cognitive processing speed during probabilistic category learning was determined by subtracting perceptual-motor control task reaction time (RT) from probabilistic category learning RT and dividing by perceptual-motor control task RT. the group-by-condition interaction analyses: the BOLD response was much greater bilaterally at the level of the prefrontal cortex (ventrolateral and dorsolateral), caudate, and cingulate in young adults throughout the entire experimental session (Fig. $3 a, b)$ ). In contrast, the older adults showed a greater BOLD response of parietal cortices bilaterally over the four quartiles during probabilistic category learning (Fig. 3b).

See Figure 4 for representative slices reaction time during the perceptual-motor control task demonstrated a significant main effect of group $\left(F_{(1,31)}=6.08 ; p=\right.$ $0.02)$, a significant main effect of trial $\left(F_{(3,93)}=4.27 ; p<0.01\right)$, and no significant group-by-trial interaction $\left(F_{(3,93)}=1.86 ; p=\right.$ 0.14 ) (see Table 2 for the mean reaction time and SE at each quartile during the perceptual-motor control task). A post hoc Fisher's LSD test of the significant main effect of group revealed that the older participants were significantly slower than the younger ones $(p=0.02)$. Results of a separate independent $t$ test for the number of trials on which no responses were made during the perceptual-motor control task displayed no significant group difference between young (mean, $0.1 ; \mathrm{SD}, 0.5$ ) and older (mean, $3.5 ; \mathrm{SD}, 12.1)$ adults $\left(t_{(31)}=1.18 ; p=0.25\right)$. ANOVA of the mean-adjusted reaction time (representing cognitive processing speed) displayed no significant main effect of group $\left(F_{(1,31)}=\right.$ $0.96 ; p=0.34)$, no significant main effect of quartile $\left(F_{(3,93)}=\right.$ $1.12 ; p=0.35)$, and no significant group-by-quartile interaction $\left(F_{(3,93)}=0.74 ; p=0.53\right.$ ) (see Table 2 for probabilistic category learning cognitive processing means for healthy young and older adults).

Results from the strategy analyses over the last 48 trials revealed that there was no significant difference between strategy use of young and older adults (with nine young and six older adults fitting a one-cue strategy, seven young and nine older adults fitting no detectable strategy use, and two young adults fitting a singleton strategy). Thus, a $2 \times 2$ (young/older adults, one-cue/no detectable strategy) $\chi^{2}$ analysis demonstrated no significant difference between groups with respect to the strategy used $\left[\chi^{2}(1 ; n=31)=0.82 ; p=0.37\right]$. Using $t$ tests to compare the groups on other strategy variables revealed no significant differences between young and older adults with respect to the number of strategies used (young: mean, 1.4; SD, 1.0; older adult: mean, $\left.1.1 ; \mathrm{SD}, 0.9 ; t_{(31)}=1.15 ; p=0.26\right)$ and no significant difference on a measure of consistent/reliable strategy use (current strategy use relative to the strategy applied over the last 20 trials) (young: mean, 0.5 ; SD, 0.4 ; older adult: mean, 0.5 ; SD, $\left.0.3 ; t_{(31)}=0.03 ; p=0.98\right)$.

\section{Imaging}

Consistent with previous studies (Poldrack et al., 1999, 2001), the spatial distribution of the task-related responses involved the bilateral prefrontal cortex [Brodmann's area (BA) 9/10, 44-46, and 47 ), supplementary motor area, premotor cortices (BA 6/8), posterior cingulate, parietal cortices (BA 40), bilateral caudate nucleus, and thalamus, although both cortical and subcortical structures showed substantially different responses over time (see Table 3 for Talairach coordinates and $Z$ scores). At the group level, the main effect of condition during the four quartiles mapped onto similar locales in each group. However, there were significant differences in the activation of different brain regions between the two groups. Group differences were most striking in showing the correlation of the BOLD response with percentage correct and reaction time during the weather prediction test. The patterns of correlations shown in Table 4 suggest performancerelated activation that includes, but is not restricted to, frontostriatal circuitry in healthy young adults and frontoparietal circuitry in healthy older adults during probabilistic category learning. In the young adults, the percentage correct was positively correlated with activation of the dorsolateral prefrontal cortex (quartiles 2-4), inferior prefrontal cortex (quartiles 1-4), caudate nucleus, parietal cortex (quartiles 1 and 2), Broca's area (quartile 3), and thalamus (quartiles 1, 2, and 4). In the older adults, the percentage correct was positively correlated with activation of the prefrontal cortex (quartiles 2 and 4), dorsolateral prefrontal cortex (quartile 1), caudate nucleus, presupplementary motor area (quartile 2), and parietal cortex (quartiles 1-4). Reaction times were positively correlated with activation of the prefrontal cortex, premotor cortex (quartile 4), medial frontal cortex (quartiles 1 and 4), cingulate cortex (quartiles 1 and 2), caudate nucleus, occipital cortex (quartiles 1-4), parietal cortex, and thalamus (quartiles 3 and 4 ) in young adults. In older adults, reaction times were positively correlated with activation of prefrontal cortex, parietal cortex (quartiles 1-4), thalamus (quartiles 1 and 3), and occipital cortex (quartile 4).

\section{Discussion}

Similar to previous imaging studies of probabilistic category learning using the weather prediction task in healthy young participants (Poldrack et al., 1999, 2001), the current study obtained activation of the bilateral dorsolateral and inferior prefrontal cortices, medial prefrontal cortex, bilateral anterior prefrontal cortex, bilateral occipital cortex, posterior cingulate, parietal cortices (BA 40), and critically, bilateral caudate nucleus. In addition, activation was also noted in the supplementary motor area, premotor cortex (BA 6/8), and thalamus in healthy young adults.

Whereas healthy older adults activate a neural network during probabilistic category learning that is similar to the network activated by healthy young adults, healthy older adults appear to activate the brain regions in the network to a differential degree relative to healthy young adults. This differential activation of a similar neural network combined with equivalent learning and performance during probabilistic category learning would suggest that some brain regions, such as the parietal cortices, displaying greater activation in older adults relative to younger adults may provide a compensatory mechanism in older adults. Consistent with previous studies demonstrating preserved nondeclarative learning and memory in older adults (Howard and Howard, 1992; La Voie and Light, 1994; Light et al., 1995; Gabrieli, 1996), the current study did not demonstrate nondeclarative probabilistic category learning or performance deficits in older adults, despite their overall slower response times. This similarity in probabilistic category learning between young and older adults 
Table 3. Significant BOLD fMRI responses for interactions between groups during the four quartiles

\begin{tabular}{|c|c|c|c|c|c|c|c|c|}
\hline \multirow[b]{2}{*}{ Comparisons } & \multicolumn{2}{|l|}{ Quartile 1} & \multicolumn{2}{|l|}{ Quartile 2} & \multicolumn{2}{|l|}{ Quartile 3} & \multicolumn{2}{|l|}{ Quartile 4} \\
\hline & $\begin{array}{l}\text { Talairach } \\
\text { coordinates }(x, y, z)\end{array}$ & Zscore & $\begin{array}{l}\text { Talairach } \\
\text { coordinates }(x, y, z)\end{array}$ & Zscore & $\begin{array}{l}\text { Talairach } \\
\text { coordinates }(x, y, z)\end{array}$ & Zscore & $\begin{array}{l}\text { Talairach } \\
\text { coordinates }(x, y, z)\end{array}$ & Z score \\
\hline \multicolumn{9}{|c|}{ Young $>$ older adults } \\
\hline BA 10 & & & $-26,47,14$ & 3.38 & $-30,47,14$ & 3.15 & $-28,49,14$ & 3.63 \\
\hline BA 9 and 46 & $\pm 55,22,24$ & 3.12 & $\pm 36,25,28$ & 3.23 & $\pm 32,10,42$ & 3.93 & $-28,23,34$ & 3.31 \\
\hline BA 44 & & & $51,18,10$ & 2.24 & $53,9,27$ & 2.79 & $-48,1,24$ & 2.91 \\
\hline BA 47 & $-30,24,-14$ & 2.53 & $\pm 40,21,-1$ & 4.20 & & & $40,15,-11$ & 3.85 \\
\hline BA 6 and 8 & $\pm 2,35,35$ & 5.30 & $\pm 12,33,42$ & 2.77 & $32,7,58$ & 3.36 & $0,31,35$ & 3.24 \\
\hline Caudate & $\pm 16,8,14$ & 3.15 & $\pm 14,6,12$ & 3.76 & $\pm 10,10,8$ & 4.18 & $\pm 14,16,5$ & 2.97 \\
\hline BA 32 and 24 & $+10,32,26$ & 4.05 & $\pm 12,27,28$ & 4.14 & $\pm 12,32,28$ & 3.64 & $8,30,24$ & 2.88 \\
\hline \multicolumn{9}{|c|}{ Older $>$ young adults } \\
\hline BA 10 & & & $32,55,21$ & 2.30 & & & & \\
\hline BA 9 and 46 & & & $44,32,30$ & 2.89 & & & $\pm 47,40,22$ & 3.10 \\
\hline BA 44 & & & & & $36,11,29$ & 2.38 & & \\
\hline BA 47 & & & & & $48,20,-6$ & 3.16 & & \\
\hline BA 6 and 8 & & & $42,-2,35$ & 2.41 & $57,-21,38$ & 3.06 & & \\
\hline BA 40 and 19 & $\pm 22,70,33$ & 2.51 & $\pm 32,-80,39$ & 3.08 & $\pm 32,-80,39$ & 2.90 & $\pm 26,-77,42$ & 3.13 \\
\hline Caudate & & & & & & & $12,-5,8$ & 1.90 \\
\hline Thalamus & $\pm 6,-6,4$ & 2.48 & $\pm 12,-2,7$ & 2.51 & & & & \\
\hline
\end{tabular}

argues against task difficulty as being a potential confound that is responsible for the observed differences in activation between young and older adults.

A compensatory interpretation is consistent with imaging studies of declarative learning showing the ability of intact circuits to compensate for age-related alterations in task-specific canonical brain regions (for review, see Della-Maggiore et al., 2002; Buckner, 2004). In a previous study of declarative learning using a test of working memory, young adults displayed greater dorsolateral prefrontal cortex activation than older adults, whereas older adults performing at the same level display greater rostral prefrontal cortex activation than young adults (Rypma et al., 2001). Similarly, during recall of recently studied words, low-performing older adults inefficiently recruited a network similar to young adults; however, high-performing older adults used bilateral regions of the prefrontal cortex (Cabeza et al., 2002; Rosen et al., 2002). Thus, even before there is evidence of decline in performance, regionally specific loss of function can lead to a functional reorganization of neural connectivity providing a corresponding preservation of performance. Results from the current study of probabilistic category learning support this view and suggest that healthy older adults use the same neural network as young adults, albeit to differential degrees to attain equivalent learning and performance.

Non-human primate studies have shown the prefrontal and posterior parietal cortices to be densely and reciprocally connected (Barbas and Mesulam, 1981; Petrides and Pandya, 1984; Schwartz and Goldman-Rakic, 1984; Andersen et al., 1985, 1990; Barbas, 1988; Cavada and Goldman-Rakic, 1989; Schall et al., 1995; Stanton et al., 1995) and that projections from the dorso-

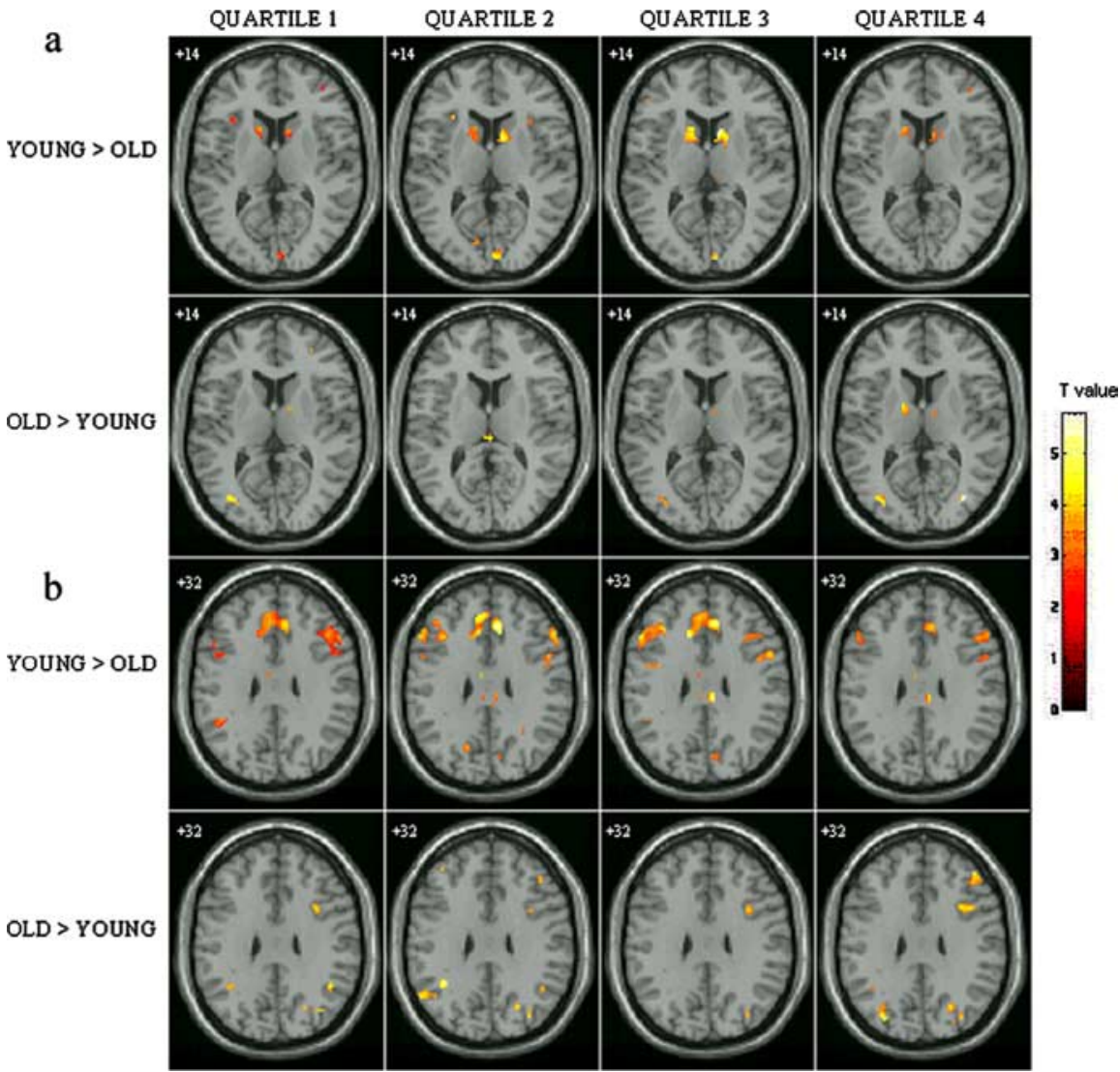

Figure 3. Statistical parametrical maps illustrating a significantly greater BOLD response in the caudate nucleus $(\boldsymbol{a})$ of the young relative to older adults ( $p<0.05$ uncorrected) and anterior and posterior cingulate gyri and bilateral prefrontal cortices $(\boldsymbol{b})$ in the young relative to older adults ( $p<0.05$ uncorrected). Conversely, there is significantly greater BOLD response of the bilateral parietal regions in the older compared with the young adults.

lateral prefrontal and parietal cortices converge on the neostriatum (Selemon and Goldman-Rakic, 1985, 1988). Previous nonhuman primate studies have found that when the parietal and prefrontal cortices are recruited in a common task, there is a duplication of neuronal receptive fields and other aspects of taskrelated activity (Chafee and Goldman-Rakic, 1998) in addition to a symmetrical exchange of neuronal signaling (Chafee and 


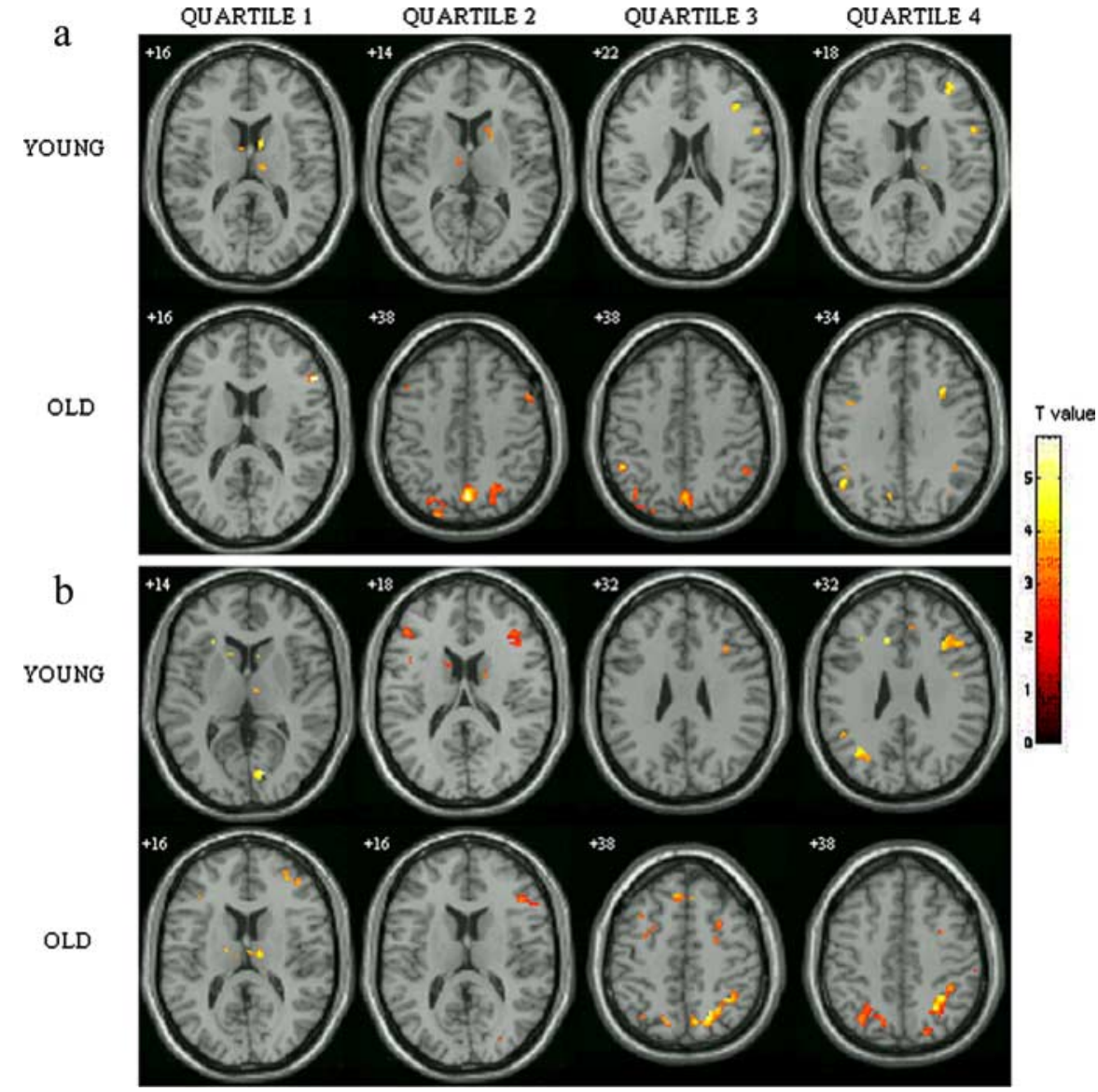

Figure 4. Representative slices showing a positive correlation of the BOLD response with the percentage correct $(\boldsymbol{a})$ and reaction time $(\boldsymbol{b})(p<0.05$ uncorrected).

Goldman-Rakic, 2000). Thus, it is anatomically conceivable that the parietal cortex is in a position to compensate for a compromised prefrontal cortex during the maintenance and application of learned probabilistic associations in older adults.

However, the role of the prefrontal cortex in probabilistic category learning remains unclear. If the prefrontal cortex is engaged in declarative processing during probabilistic category learning, rendering it irrelevant to the processing necessary to perform well on this nondeclarative learning task, then a reduction in prefrontal cortex activation as observed in the healthy older adults would not detract from learning. In fact, Knowlton et al. (1996a) found that probabilistic category learning in frontal lobe patients was equivalent to the learning of healthy agematched participants. If prefrontal cortex processing is unnecessary to produce normal probabilistic category learning, then parietostriatal circuitry may be more crucial to obtain normal learning on this task. Although the parietal-caudate circuitry may be inefficient in healthy older adults, recruitment of the adjacent parietal cortex by healthy older adults may be compensatory in nature. Future studies will be needed to differentiate the role of the prefrontal and parietal cortices during probabilistic category learning.

Updating of the probabilistic associations was believed to occur primarily in the caudate nucleus because patients with Parkinson's and Huntington's diseases failed to display normal learning during early trials of the task (Knowlton et al., 1996a,b). Additionally, in an fMRI study, Moody et al. (2004) showed less caudate nucleus activation in patients with Parkinson's disease relative to healthy age-matched adults. Correlation of the learning measures of the percentage correct and reaction time with posterior parietal regions in lieu of correlations of learning with the caudate nucleus in the older adults would support the view that the parietal cortices function in a compensatory manner for a deficient caudate response in older adults, which enables equivalent performance to young adults. As a somatosensory association area, the parietal cortex may be in a unique position to learn the probabilistic associations in the context of age-related caudate nucleus dysfunction.

An alternate interpretation of these results may suggest that older adults could use a different encoding strategy that would account for the obtained differences in correlation between caudate/parietal activation and learning in the young and older adult groups. A comparison of the different strategies used between groups demonstrated that strategy differences did not account for the different activation patterns. Results from the present study indicate that one-cue responding was the most prevalent strategy used by young and older adults. Although $80 \%$ of the participants from the study of Gluck et al. (2002) initially used a singleton strategy, there was a tendency to use the more efficient multi-cue strategy over time. However, across all training blocks, 50$60 \%$ of their participants also used a onecue strategy during the final trial blocks (Gluck et al., 2002), which corresponds well to the use of the one-cue strategy in the present study. Therefore, the present finding of equivalent proportions of young and older participants using similar strategies to solve the probabilistic category learning task further supports the interpretation of differential activation of a similar neural network in young and older adults, representing a neurophysiological- rather than a purely cognitive-driven compensatory mechanism on behalf of the older participants. This finding also supports the previous work of Rypma et al. (2005) showing minimal differences between healthy young and older adults in relation to prefrontal neural correlates of cognitive strategy use during a working memory test.

The percentage correct and reaction time learning curves did not differ between young and older adults; however, as expected, the older adults displayed age-related slower reaction times overall during both the probabilistic category learning and perceptual-motor control tasks. Results of the ANOVA on adjusted reaction time difference scores representing cognitive processing speed did not display any significant differences between groups. Although there was a significant difference between the young and older adults with respect to the number of "no responses" during probabilistic category learning, as mentioned previously, the mean number of no responses produced by the older adults was very low and comprised $<2 \%$ of the total number of trials.

Decreases in brain volume, cerebral metabolism, and blood flow have been found to occur with aging (Leenders et al., 1990; 
Table 4. Positive correlations of percentage correct and reaction time with the BOLD response during the probabilistic category learning test

\begin{tabular}{|c|c|c|c|c|c|c|c|c|}
\hline \multirow[b]{2}{*}{ Regions } & \multicolumn{2}{|l|}{ Quartile 1} & \multicolumn{2}{|l|}{ Quartile 2} & \multicolumn{2}{|l|}{ Quartile 3} & \multicolumn{2}{|l|}{ Quartile 4} \\
\hline & $\begin{array}{l}\text { Talairach } \\
\text { coordinates }(x, y, z)\end{array}$ & Zscore & $\begin{array}{l}\text { Talairach } \\
\text { coordinates }(x, y, z)\end{array}$ & Zscore & $\begin{array}{l}\text { Talairach } \\
\text { coordinates }(x, y, z)\end{array}$ & Zscore & $\begin{array}{l}\text { Talairach } \\
\text { coordinates }(x, y, z)\end{array}$ & Zscore \\
\hline $\begin{array}{l}\text { Young adults }^{a} \\
\text { PFC } \\
\text { Medial frontal cortex }\end{array}$ & & & & & & & & \\
\hline Dorsolateral PFC & & & $-30,42,16$ & 3.41 (BA 46) & $-36,46,16$ & 1.87 (BA 46) & $-32,50,16$ & 2.68 (BA 46) \\
\hline $\begin{array}{l}\text { Inferior frontal cortex } \\
\text { Cingulate cortex }\end{array}$ & $-44,22,0$ & 3.30 (BA 47) & $-38,24,-6$ & 3.05 (BA 47) & $40,24,-4$ & 2.88 (BA 47) & $-38,26,-10$ & 2.93 (BA 47) \\
\hline $\begin{array}{l}\text { Broca's area } \\
\text { Insula }\end{array}$ & & & & & $-52,12,20$ & 1.87 (BA 44) & & \\
\hline Caudate nucleus & $-6,2,14$ & 2.78 & $16,14,4$ & 2.00 & & & & \\
\hline Parietal cortex & $-40,-44,40$ & 2.21 (BA 40) & $42,-40,32$ & 2.45 (BA 40) & & & & \\
\hline $\begin{array}{l}\text { Thalamus } \\
\text { Pre-SMA } \\
\text { Premotor cortex } \\
\text { Occipital cortex }\end{array}$ & $-10,-18,16$ & 2.25 & $10,-4,4$ & 3.98 & & & $-8,-16,12$ & 2.69 \\
\hline Older adults ${ }^{a}$ & & & & & & & & \\
\hline $\begin{array}{l}\text { PFC } \\
\text { Medial frontal cortex }\end{array}$ & & & $34,60,6$ & 1.98 (BA 10) & & & $32,50,4$ & 3.12 (BA 10) \\
\hline $\begin{array}{l}\text { Dorsolateral PFC } \\
\text { Inferior frontal cortex } \\
\text { Cingulate cortex } \\
\text { Broca's area } \\
\text { Insula }\end{array}$ & $48,36,14$ & 1.82 (BA 46) & & & & & & \\
\hline Caudate nucleus & & & $16,0,16$ & 2.29 & & & & \\
\hline $\begin{array}{l}\text { Parietal cortex } \\
\text { Thalamus }\end{array}$ & $48,-40,34$ & 1.98 (BA 40) & $54,-50,36$ & 1.90 (BA 40) & $52,-52,48$ & 2.86 (BA 40) & $52,-50,44$ & 2.25 (BA 40) \\
\hline $\begin{array}{l}\text { Pre-SMA } \\
\text { Premotor cortex } \\
\text { Occipital cortex }\end{array}$ & & & $6,6,58$ & 2.74 (BA 6) & & & & \\
\hline Young adults ${ }^{b}$ & & & & & & & & \\
\hline PFC & & & & & & & $-34,46,12$ & 3.28 (BA 10) \\
\hline $\begin{array}{l}\text { Medial frontal cortex } \\
\text { Dorsolateral PFC } \\
\text { Inferior frontal cortex }\end{array}$ & $12,30,42$ & 2.62 (BA 8) & & & & & $12,32,42$ & 3.36 (BA 8) \\
\hline $\begin{array}{l}\text { Cingulate cortex } \\
\text { Broca's area } \\
\text { Insula }\end{array}$ & $-4,38,24$ & 1.85 (BA 32) & $4,34,28$ & 2.14 (BA 32) & & & & \\
\hline $\begin{array}{l}\text { Caudate nucleus } \\
\text { Parietal cortex } \\
\text { Thalamus } \\
\text { Pre-SMA }\end{array}$ & $10,14,6$ & 2.06 & $-16,10,14$ & 2.76 & $\begin{array}{l}-12,12,14 \\
48,-42,34 \\
10,-20,16\end{array}$ & $\begin{array}{l}2.17 \\
2.32(B A 40) \\
1.73\end{array}$ & $\begin{array}{l}-18,0,16 \\
46,-42,32 \\
-10,-18,16\end{array}$ & $\begin{array}{l}3.58 \\
2.76 \text { (BA 40) } \\
1.96\end{array}$ \\
\hline $\begin{array}{l}\text { Premotor cortex } \\
\text { Occipital cortex }\end{array}$ & & & & & & & $32,-2,58$ & 3.04 (BA 6) \\
\hline $\begin{array}{l}\text { Occipital cortex } \\
\text { Older adults }\end{array}$ & $26,-90,-10$ & 3.13 (BA 18) & $32,-76,-8$ & 4.52 (BA 19) & $18,-96,0$ & 3.14 (BA 18) & $32,-78,36$ & 2.42 (BA 19) \\
\hline $\begin{array}{l}\text { PFC } \\
\text { Medial frontal cortex } \\
\text { Dorsolateral PFC } \\
\text { Inferior frontal cortex } \\
\text { Cingulate cortex } \\
\text { Broca's area } \\
\text { Insula } \\
\text { Caudate nucleus }\end{array}$ & $36,58,4$ & 2.62 (BA 10) & $32,60,6$ & 1.79 (BA 10) & $30,62,4$ & 1.91 (BA 10) & $-30,48,4$ & 2.67 (BA 10) \\
\hline $\begin{array}{l}\text { Parietal cortex } \\
\text { Thalamus } \\
\text { Pre-SMA } \\
\text { Premotor cortex }\end{array}$ & $\begin{array}{l}52,-40,42 \\
10,-10,10\end{array}$ & $\begin{array}{l}2.73(\mathrm{BA} 40) \\
2.97\end{array}$ & $-30,-50,32$ & 2.14 (BA 40) & $\begin{array}{l}28,-56,38 \\
-6,-4,10\end{array}$ & $\begin{array}{l}2.26 \text { (BA 40) } \\
2.38\end{array}$ & $-54,-54,42$ & 2.18 (BA 40) \\
\hline Occipital cortex & & & & & & & $-38,-90,4$ & 2.28 (BA 19) \\
\hline
\end{tabular}

PFC, Prefrontal cortex; SMA, supplementary motor area.

${ }^{a}$ Regions that showed a significant correlation between an increase in BOLD response and percentage correct.

${ }^{b}$ Regions that showed a significant correlation between an increase in BOLD response and reaction time.

Marchal et al., 1992; D'Esposito et al., 1999; Buckner et al., 2000; Trollor and Valenzuela, 2001). However, it is highly unlikely that such age-related changes would systematically result in group differences that are regionally dissociated (e.g., decreased activation in the caudate and prefrontal cortex along with increased parietal activation in older adults relative to younger adults). Thus, our finding of increased parietal activation in the older adults would not be expected on the basis of hemodynamic or other global changes associated with aging.

In summary, results from the present neuroimaging study 
suggest that equivalent nondeclarative probabilistic category learning in healthy young and older adults elicits differential activation of a similar neural network, involving the dorsolateral prefrontal cortex, caudate nucleus, and posterior parietal cortex. We found greater prefrontal cortex and caudate activation in healthy young adults and greater parietal cortex activation in healthy older adults. Thus, in the presence of decreased prefrontal and caudate activity during normal aging, older adults seem to be able to recruit additional resources within the parietal cortex that enables them to learn the probabilistic associations as well as young adults. These differential activation patterns within the same neural circuitry of healthy young and older adults in conjunction with equivalent learning suggests that some brain regions, such as the parietal cortex, may act in a compensatory manner for inefficient or functionally compromised areas, such as prefrontal-caudate circuitry in older adults during nondeclarative, probabilistic category learning.

\section{References}

Andersen RA, Asanuma C, Cowan WM (1985) Callosal and prefrontal associational projecting cell populations in area 7A of the macaque monkey: a study using retrogradely transported fluorescent dyes. J Comp Neurol 232:443-455.

Andersen RA, Asanuma C, Essick G, Siegel RM (1990) Corticocortical connections of anatomically and physiologically defined subdivisions within the inferior parietal lobule. J Comp Neurol 296:65-113.

Anderson ND, Iidaka T, Cabeza R, Kapur S, McIntosh AR, Craik FI (2000) The effects of divided attention on encoding- and retrieval-related brain activity: a PET study of younger and older adults. J Cogn Neurosci 12:775-792.

Aron AR, Shohamy D, Clark J, Myers C, Gluck MA, Poldrack RA (2004) Human midbrain sensitivity to cognitive feedback and uncertainty during classification learning. J Neurophysiol 92:1144-1152.

Backman L, Almkvist O, Andersson J, Nordberg A, Winblad B, Reineck R, Långstrom B (1997) Brain activation in young and older adults during implicit and explicit retrieval. J Cogn Neurosci 9:378-391.

Barbas H (1988) Anatomic organization of basoventral and mediodorsal visual recipient prefrontal regions in the rhesus monkey. J Comp Neurol 276:313-342.

Barbas H, Mesulam MM (1981) Organization of afferent input to subdivisions of area 8 in the rhesus monkey. J Comp Neurol 200:407-431.

Buckner RL (2004) Memory and executive function in aging and AD: multiple factors that cause decline and reserve factors that compensate. Neuron 44:195-208.

Buckner RL, Snyder AZ, Sanders AL, Raichle ME, Morris JC (2000) Functional brain imaging of young, nondemented, and demented older adults. J Cogn Neurosci 12 [Suppl 2]:24-34.

Cabeza R, Grady CL, Nyberg L, McIntosh AR, Tulving E, Kapur S, Jennings JM, Houle S, Craik FI (1997) Age-related differences in neural activity during memory encoding and retrieval: a positron emission tomography study. J Neurosci 17:391-400.

Cabeza R, Anderson ND, Locantore JK, McIntosh AR (2002) Aging gracefully: compensatory brain activity in high-performing older adults. NeuroImage 17:1394-1402.

Cavada C, Goldman-Rakic PS (1989) Posterior parietal cortex in rhesus monkey: II. Evidence for segregated corticocortical networks linking sensory and limbic areas with the frontal lobe. J Comp Neurol 287:422-445.

Chafee MV, Goldman-Rakic PS (1998) Matching patterns of activity in primate prefrontal area $8 \mathrm{a}$ and parietal area 7ip neurons during a spatial working memory task. J Neurophysiol 79:2919-2940.

Chafee MV, Goldman-Rakic PS (2000) Inactivation of parietal and prefrontal cortex reveals interdependence of neural activity during memoryguided saccades. J Neurophysiol 83:1550-1566.

Cohen NJ, Squire LR (1980) Preserved learning and retention of patternanalyzing skill in amnesia: dissociation of knowing how and knowing that. Science 210:207-210.

Daselaar SM, Rombouts SA, Veltman DJ, Raaijmakers JG, Jonker C (2003) Similar network activated by young and old adults during the acquisition of a motor sequence. Neurobiol Aging 24:1013-1019.

Della-Maggiore V, Grady CL, McIntosh AR (2002) Dissecting the effect of aging on the neural substrates of memory: deterioration, preservation or functional reorganization? Rev Neurosci 13:167-181.

D’Esposito M, Zarahn E, Aguirre GK, Rypma B (1999) The effect of normal aging on the coupling of neural activity to the bold hemodynamic response. NeuroImage 10:6-14.

Gabrieli JD (1996) Memory systems analyses of mnemonic disorders in aging and age-related diseases. Proc Natl Acad Sci USA 93:13534-13540.

Gluck MA, Shohamy D, Myers C (2002) How do people solve the "weather prediction" task? Individual variability in strategies for probabilistic category learning. Learn Mem 9:408-418.

Grady CL, McIntosh AR, Bookstein F, Horwitz B, Rapoport SI, Haxby JV (1998) Age-related changes in regional cerebral blood flow during working memory for faces. NeuroImage 8:409-425.

Howard DV, Howard Jr JH (1992) Adult age differences in the rate of learning serial patterns: evidence from direct and indirect tests. Psychol Aging 7:232-241.

Howard Jr JH, Howard DV (1997) Age differences in implicit learning of higher order dependencies in serial patterns. Psychol Aging 12:634-656.

Jernigan TL, Archibald SL, Berhow MT, Sowell ER, Foster DS, Hesselink JR (1991) Cerebral structure on MRI, Part I: Localization of age-related changes. Biol Psychiatry 29:55-67.

Jernigan TL, Ostergaard AL, Fennema-Notestine C (2001a) Mesial temporal, diencephalic, and striatal contributions to deficits in single word reading, word priming, and recognition memory. J Int Neuropsychol Soc 7:63-78.

Jernigan TL, Archibald SL, Fennema-Notestine C, Gamst AC, Stout JC, Bonner J, Hesselink JR (2001b) Effects of age on tissues and regions of the cerebrum and cerebellum. Neurobiol Aging 22:581-594.

Knowlton BJ, Squire LR, Gluck MA (1994) Probabilistic classification learning in amnesia. Learn Mem 1:106-120.

Knowlton BJ, Mangels JA, Squire LR (1996a) A neostriatal habit learning system in humans. Science 273:1399-1402.

Knowlton BJ, Squire LR, Paulsen JS, Swerdlow NR, Swenson M (1996b) Dissociations within nondeclarative memory in Huntington's disease. Neuropsychology 10:538-548.

La Voie D, Light LL (1994) Adult age differences in repetition priming: a meta-analysis. Psychol Aging 9:539-553.

Leenders KL, Perani D, Lammertsma AA, Heather JD, Buckingham P, Healy MJ, Gibbs JM, Wise RJ, Hatazawa J, Herold S, Beaney RP, Brooks DJ, Spinks T, Rhodes C, Frackowiak RSJ, Jones T (1990) Cerebral blood flow, blood volume and oxygen utilization. Normal values and effect of age. Brain 113:27-47.

Light LL, La Voie D, Kennison R (1995) Repetition priming of nonwords in young and older adults. J Exp Psychol Learn Mem Cogn 21:327-346.

Lustig C, Buckner RL (2004) Preserved neural correlates of priming in old age and dementia. Neuron 42:865-875.

Madden DJ, Turkington TG, Coleman RE, Provenzale JM, DeGrado TR, Hoffman JM (1996) Adult age differences in regional cerebral blood flow during visual world identification: evidence from H215O PET. NeuroImage 3:127-142.

Maki PM, Zonderman AB, Weingartner H (1999) Age differences in implicit memory: fragmented object identification and category exemplar generation. Psychol Aging 14:284-294.

Marchal G, Rioux P, Petit-Taboue MC, Sette G, Travere JM, Le Poec C, Courtheoux P, Derlon JM, Baron JC (1992) Regional cerebral oxygen consumption, blood flow, and blood volume in healthy human aging. Arch Neurol 49:1013-1020.

McIntosh AR, Sekuler AB, Penpeci C, Rajah MN, Grady CL, Sekuler R, Bennett PJ (1999) Recruitment of unique neural systems to support visual memory in normal aging. Curr Biol 9:1275-1278.

Moody TD, Bookheimer SY, Vanek Z, Knowlton BJ (2004) An implicit learning task activates medial temporal lobe in patients with Parkinson's disease. Behav Neurosci 118:438-442.

Petrides M, Pandya DN (1984) Projections to the frontal cortex from the posterior parietal region in the rhesus monkey. J Comp Neurol 228:105-116.

Poldrack RA, Prabhakaran V, Seger CA, Gabrieli JD (1999) Striatal activation during acquisition of a cognitive skill. Neuropsychology 13:564-574.

Poldrack RA, Clark J, Pare-Blagoev EJ, Shohamy D, Creso Moyano J, Myers C, Gluck MA (2001) Interactive memory systems in the human brain. Nature 414:546-550.

Raz N, Gunning FM, Head D, Dupuis JH, McQuain J, Briggs SD, Loken WJ, 
Thornton AE, Acker JD (1997) Selective aging of the human cerebral cortex observed in vivo: differential vulnerability of the prefrontal gray matter. Cereb Cortex 7:268-282.

Raz N, Rodrigue KM, Kennedy KM, Head D, Gunning-Dixon F, Acker JD (2003) Differential aging of the human striatum: longitudinal evidence. Am J Neuroradiol 24:1849-1856.

Reber PJ, Stark CE, Squire LR (1998a) Cortical areas supporting category learning identified using functional MRI. Proc Natl Acad Sci USA 95:747-750.

Reber PJ, Stark CE, Squire LR (1998b) Contrasting cortical activity associated with category memory and recognition memory. Learn Mem 5:420-428.

Reber PJ, Wong EC, Buxton RB (2002) Comparing the brain areas supporting nondeclarative categorization and recognition memory. Brain Res Cogn Brain Res 14:245-257.

Rosen AC, Prull MW, O'Hara R, Race EA, Desmond JE, Glover GH, Yesavage JA, Gabrieli JD (2002) Variable effects of aging on frontal lobe contributions to memory. NeuroReport 13:2425-2428.

Rypma B, Prabhakaran V, Desmond JE, Gabrieli JD (2001) Age differences in prefrontal cortical activity in working memory. Psychol Aging 16:371-384.

Rypma B, Berger JS, Genova HM, Rebbechi D, D’Esposito M (2005) Dissociating age-related changes in cognitive strategy and neural efficiency using event-related fMRI. Cortex 41:582-594.

Schacter DL, Savage CR, Alpert NM, Rauch SL, Albert MS (1996) The role of hippocampus and frontal cortex in age-related memory changes: a PET study. NeuroReport 7:1165-1169.

Schall JD, Morel A, King DJ, Bullier J (1995) Topography of visual cortex connections with frontal eye field in macaque: convergence and segregation of processing streams. J Neurosci 15:4464-4487.
Schwartz ML, Goldman-Rakic PS (1984) Callosal and intrahemispheric connectivity of the prefrontal association cortex in rhesus monkey: relation between intraparietal and principal sulcal cortex. J Comp Neurol 226:403-420.

Selemon LD, Goldman-Rakic PS (1985) Longitudinal topography and interdigitation of corticostriatal projections in the rhesus monkey. J Neurosci 5:776-794.

Selemon LD, Goldman-Rakic PS (1988) Common cortical and subcortical targets of the dorsolateral prefrontal and posterior parietal cortices in the rhesus monkey: evidence for a distributed neural network subserving spatially guided behavior. J Neurosci 8:4049-4068.

Squire LR (1992a) Declarative and nondeclarative memory: Multiple brain systems supporting learning and memory. J Cogn Neurosci 4:232-243.

Squire LR (1992b) Memory and the hippocampus: a synthesis from findings with rats, monkeys, and humans. Psychol Rev 99:195-231.

Stanton GB, Bruce CJ, Goldberg ME (1995) Topography of projections to posterior cortical areas from the macaque frontal eye fields. J Comp Neurol 353:291-305.

Trollor JN, Valenzuela MJ (2001) Brain ageing in the new millennium. Aust NZ J Psychiatry 35:788-805.

van Dyck CH, Seibyl JP, Malison RT, Laruelle M, Zoghbi SS, Baldwin RM, Innis RB (2002) Age-related decline in dopamine transporters: analysis of striatal subregions, nonlinear effects, and hemispheric asymmetries. Am J Geriatr Psychiatry 10:36-43.

Volkow ND, Gur RC, Wang GJ, Fowler JS, Moberg PJ, Ding YS, Hitzemann R, Smith G, Logan J (1998) Association between decline in brain dopamine activity with age and cognitive and motor impairment in healthy individuals. Am J Psychiatry 155:344-349. 